\title{
Anatomical relationship between Kambin's triangle and exiting nerve root
}

\author{
Masataka Sakane \\ Department of Orthopaedic Surgery, Tsukuba Gakuen Hospital, Tsukuba 305-0854, Japan.
}

Correspondence to: Dr. Masataka Sakane, Department of Orthopaedic Surgery, Tsukuba Gakuen Hospital, 2573-1 Kamiyokoba, Tsukuba 305-0854, Japan. E-mail: sakane-m@tsukuba-seikei.jp

How to cite this article: Sakane M. Anatomical relationship between Kambin's triangle and exiting nerve root. Mini-invasive Surg 2017;1:99-102.

Article history: Received: 5 May 2017 Accepted: 10 May $2017 \quad$ Published: 30 Sep 2017

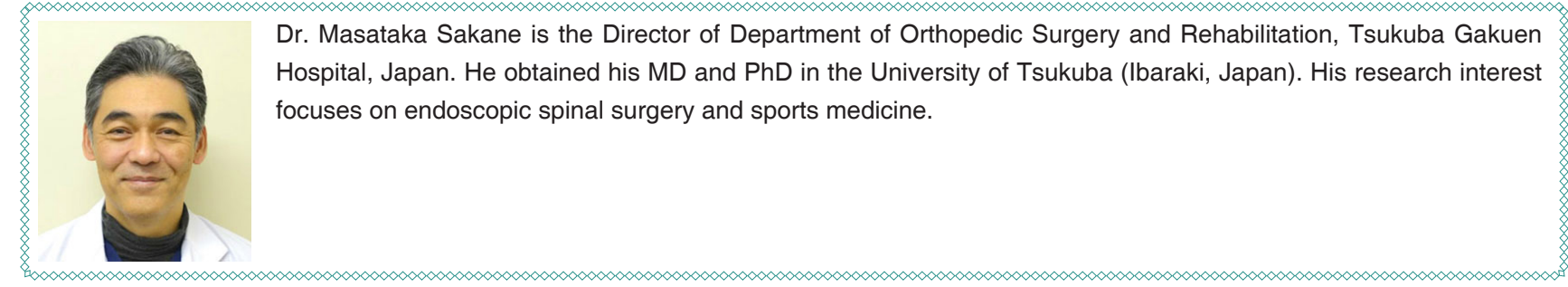

\section{INTRODUCTION}

Percutaneous endoscopic lumbar discectomy (PELD) was introduced by Kambin and Brager ${ }^{[1]}$ and Hijikata et al. ${ }^{[2]}$ prior to the 1980 s and is a minimally invasive technique for lumbar disc herniation. Many clinical reports have indicated that PELD is preferable to conventional open techniques. ${ }^{[3-5]}$

There are three approaches for PELD: transforaminal, interlaminal, and posterolateral. Transforaminal and interlaminar approaches are mainly used for intracanal disc herniation. The transforaminal approach is also used for foraminal disc herniation, while the posterolateral approach is used for extraforaminal lesions. The transforaminal approach is typically used to access intervertebral discs through the foramen without sacrificing the paravertebral muscles and facet joint. In 1983, Kambin and Gellmann ${ }^{[6]}$ described a safety triangle called "Kambin's triangle" for the transforaminal approach.

Kambin's triangle is a three-dimensional anatomical right triangle located over the dorsolateral intervertebral disc of the lumbar spine. This concept is widely accepted for not only PELD but also epidural injection and interbody fusion techniques. In an L4-L5 disc herniation, the L4 nerve root forms the hypotenuse of the Kambin's triangle, which maybe at potential risk for injury.

\section{ANATOMY OF KAMBIN'S TRIANGLE}

Kambin's safety zone is the area surrounding the superior endplate of the inferior vertebral body, superior articulating facet, and exiting nerve root (ENR) [Figure 1]. Based on specimens from cadavers, this review discusses the anatomical orientation, area, and diameter of Kambin's safety zone and limitations of the transforaminal approach.[7] License (https://creativecommons.org/licenses/by/4.0/), which permits unrestricted use, distribution, and reproduction in any medium, as long as the original author is credited and the new creations are licensed under the identical terms. 
In 1995, Mirkovic et al. ${ }^{[8]}$ clarified that a working cannula could be safety placed in line with the medial onethird of corresponding pedicle. Min et al ${ }^{[9]}$ reported an average distance of $11.6 \mathrm{~mm}$ between the ENR and the superior articulating process. Hoshide et al. ${ }^{[10]}$ also measured the height and width of 16 Kambin's safety triangles from 2 cadavers by closely penetrating intervertebral discs using a standard posterolateral approach with a Kirschner wire under fluoroscopic assistance. At the time of open dissection, there was no ENR injury from the wire insertion. They showed averaged Kambin's safety zone areas of $60,71.5$, 93.5, and $108 \mathrm{~mm}^{2}$ at L1-L2, L2-L3, L3-L4, and L4L5 levels, respectively. Hardenbrook et al. ${ }^{[11]}$ also analyzed Kambin's safety zone areas by removing the top of a superior facet from 8 fresh-frozen female cadaveric specimens, and reported averaged areas of 115, 120, 119, and $116 \mathrm{~mm}^{2}$ at L1-L2, L2-L3, L3-L4, and L4-L5 levels, respectively. They concluded that Kambin's working triangle was a relatively large area for minimally invasive transforaminal interbody fusion. On the other hand, Ozer et al. ${ }^{[12]}$ performed both cadaveric measurements and surgical observations of Kambin's safety zone. They observed only $17.6 \%$ and $10.8 \%$ of "wide" safety zones of cadaveric measurements and surgical observations, respectively and concluded that there were large variations in Kambin's triangle. Furthermore, there was no space inside the triangle in approximately one-third of L2-L5 in cadaveric (15/48) and surgical specimens (11/34). They suggested using a partial superior facetectomy to avoid ENR injury [Figure 2].
Arslan et al. ${ }^{[13]}$ also showed anatomical variation in the distance between the ENR and pedicle and the height and width of intervertebral foramen from L1-L2 to L5-S1 in 14 male formalin-fixed cadavers.

\section{ENR INJURY}

ENR injury is the most devastating complication of transforaminal PELD. In 2002, Yeung and Tsou ${ }^{[3]}$ reported on surgical outcomes and complications. The rate of postoperative dysesthesia (POD) was $1.9 \%(6 / 307)$ with a $6-\mathrm{mm}$ scope. Ruetten et al. ${ }^{[4]}$ reported $\mathrm{POD}$ in $1(1.8 \%)$ out of 41 patients with an 8-mm cannula under general anesthesia. Ahn et al. ${ }^{[14,15]}$ reported that POD occurred as a complication of PELD under local anesthesia and sedation in $4.7 \%$ of recurrent herniated cases and in $6.7 \%$ of upper lumbar lesion cases. In their early case series of transforaminal PELD with an 8-mm diameter scope, Abe et al. ${ }^{[16]}$ reported that $2(9.6 \%)$ and $4(19 \%)$ of 22 patients experienced POD after surgery under general and local anesthesia, respectively. Although they used a contrast material injection technique in the epidural space to determine the ENR anatomy during surgery, it did not prevent nerve irritation. ${ }^{[17]}$

Choi et al. ${ }^{[18]}$ evaluated clinical-radiological features indicating a risk of root injuries for proposed transforaminal endoscopic discectomy. In their retrospective analysis of 233 patients treated with PELD for lumbar disc herniation, 20 (4.7\%) patients exhibited postoperative exiting root-related dysesthesias or motor weakness. They did not

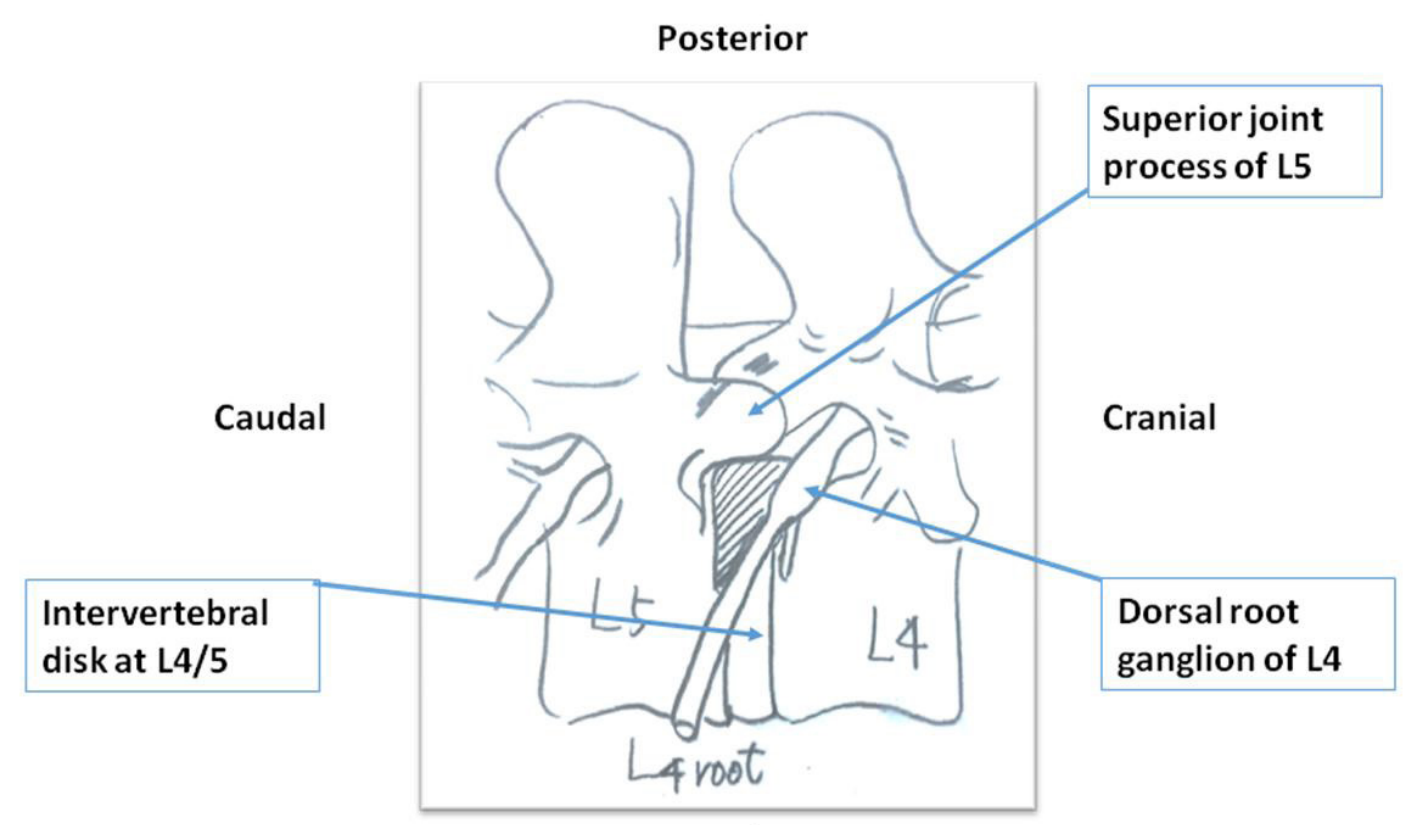

Anterior

Figure 1: Kambin's safety triangle (shaded area) at L4/L5 


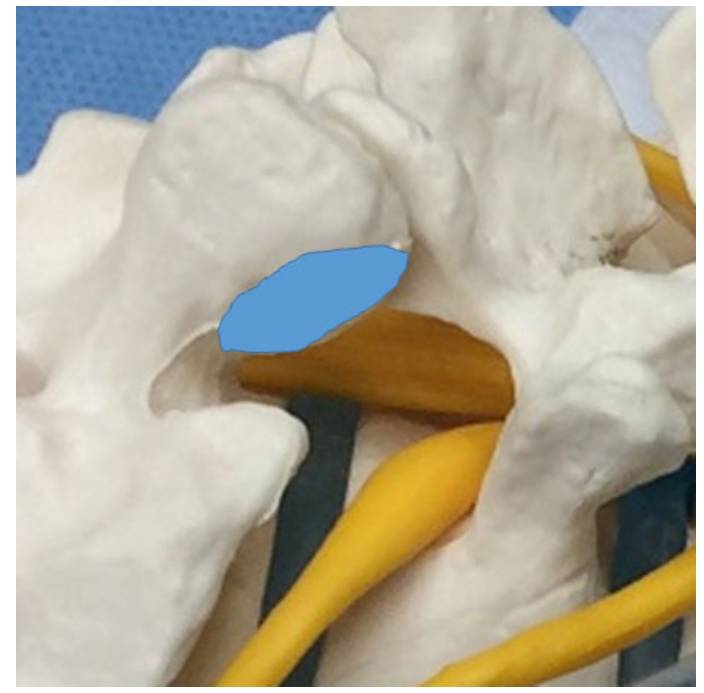

Figure 2: Partial fecetectomy to widen transforaminal space. An area of partial fecetectomy is colored by blue

describe about the type of anesthesia used during the surgery. Magnetic resonance imaging (MRI) revealed that patients sustaining ENR injuries had a shorter distance between the ENR and the lower facet. They recommended that measuring this distance during preoperative MRI studies may allow surgeons to choose more optimal approaches. Recently, the diffusion tensor imaging technique has been used for the structural and functional diagnosis of lumbar nerve damage before and after surgery. ${ }^{[19-23]}$

Regarding surgical procedures, Cho et al. ${ }^{[24]}$ demonstrated that their floating technique reduces complications during PELD. In their series of 154 patients, none had ENR injury. They recommended that the guide needle should be attached to the lateral aspect of the superior facet for the insertion of dilators and cannula before accessing the annulus.

Sairyo et al. ${ }^{[25]}$ have reported on their initial 100 cases of PELD under local anesthesia. In this series, 2 patients $(2 \%)$ complained of leg pain and dysesthesia 2 days after surgery, although the pain disappeared within 3 months after conservative treatment. They proposed 2 etiologies of POD, direct exiting nerve injury with the needle and/or cannula insertion and irritation of the dorsal root ganglion due to compression by the cannula. They also emphasized that the guide needle should touch a caudal pedicle before needling Kambin's triangle, as this "walking technique" prevents POD [Figure 3].

Using a surgical bur through the working portal of the endoscope, full endoscopic partial laminectomy has been performed more frequently. Converting from a translaminar to an interlaminar approach is a reasonable option. In 2015 , Li et al. ${ }^{[26]}$ evaluated

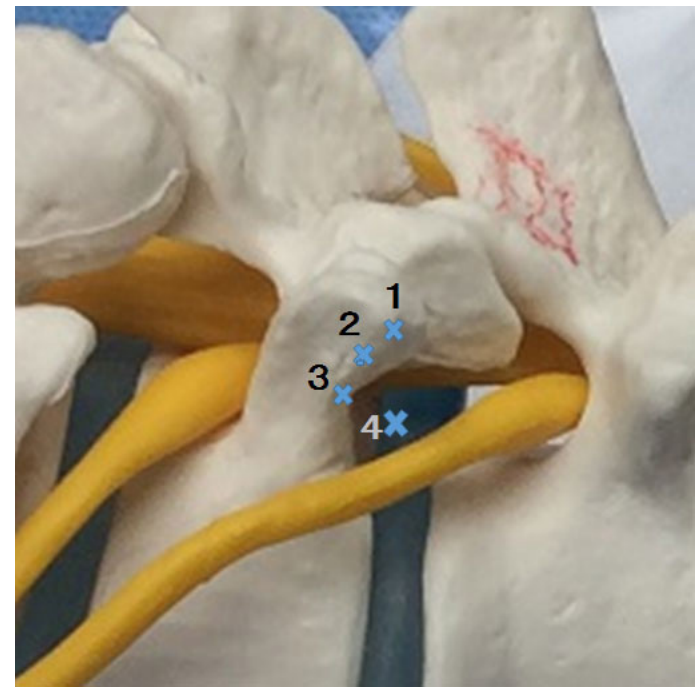

Figure 3: Walking technique. A guide needle is place on the superior facet $(X 1)$. Then surgeon moves needle on the $X 2, X 3$, and $\mathrm{X} 4$ point to avoid touching the exiting nerve root

the efficacy of fully endoscopic interlaminar L5-S1 discectomy in 72 patients with axillary, ventral, or shoulder types/locations of disc herniation. They used postoperative MRI to confirm the extent of resection. Complications included 1 disc recurrence, but there were no nerve root injuries and infections.

\section{DISCUSSION}

PELD has the advantages of shorter hospital stay and a lower risk of infection compared with standard surgical procedures, such as open or micro discectomy for lumbar disc herniation. ${ }^{[27]}$

However, the large spine patient outcomes research trial conducted by Desai et al. ${ }^{[28]}$ showed the frequency of nerve root injury following an open discectomy ranged from $0.13 \%$ to $0.25 \%$. For open laminectomy or stenosis with or without fusion, it was $0 \%$ and for open laminectomy or stenosis or degenerative spondylolisthesis with or without fusion it was $2 \%$.

Most minimal invasive surgeries for lumbar disc herniation have higher frequencies of radiculitis and/ or nerve root injuries compared with conventional open surgery. ENR injury is the most devastating complication of transforaminal PELD, and rates of injury up to $20 \%$ have been reported.

ENR injury causes POD and motor weakness and reduces physical function and overall satisfaction of the patient. Therefore, the prevention of ENR injury is important for achieving a higher rate of clinical success.

Under fluoroscopy, surgeons are not able to see one border of ENR in Kambin's triangle. Careful 
preoperative neurological examination combined with MRI helps to characterize three-dimensional anatomy of the Kambin's safety zone and to choose between transforaminal and interlaminar techniques.

During transforaminal endoscopic surgery, precise needle placement and the use of additional techniques, such as foraminoplasty using a high-speed bur, to widen the bottom line of Kambin's triangle would help in safely approaching intervertebral discs with short prolongation of operative time.

\section{DECLARATIONS}

\section{Authors' contributions \\ M. Sakane contributed solely to the paper.}

\section{Financial support and sponsorship None.}

\section{Conflicts of interest \\ There are no conflicts of interest.}

\section{Patient consent Not applicable.}

\section{Ethics approval Not applicable.}

\section{REFERENCES}

1. Kambin P, Brager MD. Percutaneus posterolateral discectomy. Anatomy and mechanism. Clin Orthop Relat Res 1987;223:145-54.

2. Hijikata S, Yamagishi M, Nakayama T, Oomori K. Percutaneous nucleotomy: a new treatment method for lumbar disc herniation. $J$ Toden Hop 1975;5:5-13.

3. Yeung AT, Tsou PM. Posterolateral endoscopic excision for lumbar disc herniation. Surgical technique, outcome, and complications in 307 consecutive cases. Spine (Phila Pa 1976) 2002;27:722-31.

4. Ruetten S, Komp M, MerkH, Godolias G. Full-endoscopic interlaminar and transforaminal lumbar discectomy versus conventional microsurgical technique: a prospective randomized, control study. Spine (Phila Pa 1976) 2008;33:931-9.

5. Hermantin FU, Peters T, Quartararo L, Kambin P. A prospective randomized study comparing the results of open discectomy with those of video-assisted arthroscopic microdiscectomy. J Bone Joint Surg Am 1999;81:958-65.

6. Kambin P, Gellmann H. Percutaneous lateral discectomy of the lumber spine: a preliminary report. Clin Orthop Relat Res 1983;174:127-32.

7. Kambin P, Nixon JE, Chait A, Schaffer JL. Annular protrusion: pathophysiology and roentgenographic appearance. Spine (Phila Pa 1976) 1988;13:671-5.

8. Mirkovic SR, Schwartz DG, Glazier KD. Anatomic considerations in lumbar posterolateral percutaneous procedures. Spine (Phila Pa 1976) 1995;20:1965-71.

9. Min JH, Kang SH, Lee JB, Cho TH, Suh JK, Rhyu IJ. Morphometric analysis of the working zone for endoscopic lumbar discectomy. $J$ Spinal Disord Tech 2005;18:132-5.

10. Hoshide R, Feldman E, Taylor W. Cadaveric analysis of the Kambin's triangle. Cureus 2016;8:e475.
11. Hardenbrook M, Lombardo S, Wilson MC, Telfeian A. The anatomical rationale for transforaminal endoscopic interbody fusion: a cadaveric analysis. Neurosurg Focus 2016;40:E12.

12. Ozer AF, Suzer T, Falsafi M, Aydin M, Sasani M, Oktennoglu T. Anatomic assessment of variations in Kambin'striangle: a surgical and cadaveric study. World Neurosurg 2017;100:498-503.

13. Arslan M, Comert A, Acar HI, Ozdemir M, Elhan A, Tekdemir I, Tubbs RS, Ugur HC. Nerve root to lumbar disc relationships at the intervertebral foramen from a surgical viewpoint: an anatomical study. Clin Anat 2012;25:218-23.

14. Ahn Y, Lee SH, Park WH, Lee HY, Shin SW, Kang HY. Percutaneous endoscopic lumbar discectomy for recurrent disc herniation: surgical technique, outcome, and prognostic factors of 443 consecutive cases. Spine 2004;15:E326-32.

15. Ahn Y, Lee SH, Lee JH, Kim JU, Liu WC. Transforaminal percutaneous endoscopic lumbar siscectomy for upper lumbar disc herniation: clinical outcome, prognostic factors, and technical consideration. Acta Neurochir (Wien) 2009;151:199-206.

16. Abe T, Sakane M, Funayama T, Mataki Y, Takeuchi Y, Hyodo K, Koyama S, Hioki S, Yamazaki M. Clinical result of PELD via transforaminal approach under general anesthesia. J Spine Res 2013;4:1264-9. (in Japanese)

17. Manchikanti L, Cash KA, Pampati V, Damron KS, McManus CD Evaluation of lumbar transforaminal epidural injections with needle placement and contrast flow pattern: a prospective descriptive report. Pain Physician 2004;7:217-23.

18. Choi I, Ahn JO, So WS, Lee SJ, Choi IJ, Kim H. Exiting root injury in transforaminal endoscopic discectomy: preoperative image consideration for safety. Eur Spine J 2003;22:2481-7.

19. Wu W, Liang J, Chen Y, Chen A, Wu Y, Yang Z. Microstructural changes are coincident with the improvement of clinical symptoms in surgically treated compressed nerve roots. Sci Rep 2017;7:44678.

20. Eguchi Y, Oikawa Y, Suzuki M, Orita S, Yamauchi K, Suzuki M, Aoki Y, Watanabe A, Takahashi K, Ohtori S. Diffusion tensor imaging of radiculopathy in patients with lumbar disc herniation: preliminary results. Bone Joint J 2016;98:387-94.

21. Chuanting L, Qingzheng W, Wenfeng X, Yivi H, Bin Z. 3.0T MRI tractography of lumbar nerve roots in disc herniation. Acta Radiol 2014;55:969-75.

22. Budzik JF, Verclytte S, Lefebvre G, Monnet A, Forzy G, Cotten A Assessment of reduced field of view in diffusion tensor imaging of the lumbar nerve roots at 3 T. Eur Radiol 2013;23:1361-6.

23. Shi Y, Zong M, Xu X, Zou Y, Feng Y, Liu W, Wang C, Wang D. Diffusion tensor imaging with quantitative evaluation and fiber tractography of lumbar nerve roots in sciatica. Eur J Radiol 2015;84:690-5.

24. Cho JY, Lee SH, Lee HY. Prevention of development of postoperative dysesthesia in transforaminal percutaneous endoscopic lumbar discectomy for intracanalicular lumbar disc herniation: floating retraction technique. Minim Invasive Neurosurg 2011;54:214-8.

25. Sairyo K, Egawa H, Matsuura T, Takahashi M, HIgashino K, Saka T, Suzue N, Hamada D, Goto T, Takata Y, Nishisho T, Goda Y, Sato R, Tsutsui T, Tonogai I, Kondo K, Tezuka F, Mineta K, Sugiura K, Takeuchi M, Dezawa A. State of the art: transforaminal approach for percutaneous endoscopic lumbar discectomy under local anesthesia. $J$ Med Invest 2014;61:217-25.

26. Li ZZ, Hou SX, Shang WL, Song KR, Zhao HL. The strategy and early clinical outcome of full-endoscopic L5/S1 discectomy through interlaminar approach. Clin Neurol Neurosurg 2015;133:40-5.

27. Rasouli MR, Rahimi-Movaghar V, Shokraneh F, Moradi-Lakeh M, Chou R. Minimally invasive discectomy versus microdiscectomy/ open discectomy for symptomatic lumbar disc herniation. Cochrane Database Syst Rev 2014;(9):CD010328.

28. Desai A, Bekelis K, Ball PA, Lurie J, Mirza SK, Tosteson TD, Zhao W, Weinstein JN. Spine patient outcomes research trial: do outcomes vary across centers for surgery for lumbar disc herniation? Neurosurgery 2012;71:833-42. 